\title{
A cross-sectional study of the associations between the traditional Japanese diet and nutrient intakes: the NILS-LSA project
}

Shu Zhang ${ }^{*^{*}}$ (D), Rei Otsuka ${ }^{2 \dagger}$, Yasutake Tomata ${ }^{1}$, Hiroshi Shimokata ${ }^{2,3}$, Chikako Tange ${ }^{2}$, Makiko Tomida ${ }^{2}$, Yukiko Nishita ${ }^{4}$, Sanae Matsuyama ${ }^{1}$ and Ichiro Tsuji ${ }^{1}$

\begin{abstract}
Background: Although our previous study using a food frequency questionnaire simulated nutritional characteristics of the traditional Japanese diet, this issue has not been sufficiently evaluated. This study was conducted to examine the relationship between the traditional Japanese diet and nutrient density (ND).

Methods: A cross-sectional study employing the dietary record method was conducted among 2221 community-dwelling Japanese adults (40-88 years) living in Aichi Prefecture, Japan, in 2006-2008. Based on previous studies, a 9-component Japanese Diet Index (JDI) and a 12-component modified JDI ( $\mathrm{mJDI}_{12}$ ) were defined. To develop a new weighted index, a multiple linear regression model was used to select food components which were significantly associated with an ND score (integrated by 11 nutrient components) from the $\mathrm{mJDl}_{12}$ and weight them. Correlation analyses were performed between JDI, $\mathrm{mJDl}_{12}$, the new weighted JDI score and the ND score and its 11 nutrient components. The findings were validated with data from 2008 to 2010 by assessing the associations between the JDls scores and the ND score.

Results: Scores of the JDI and $\mathrm{mJDI}_{12}$ were positively correlated with the ND score (corresponding Spearman's $\rho$ [95\% confidence interval; $\mathrm{Cl}], 0.34[0.31,0.38]$ and $0.44[0.41,0.48]$, respectively; $P<0.05$ for both). Among the $\mathrm{mJDI}_{12}, 9$ food components (rice, fish and shellfish, green and yellow vegetables, seaweed, green tea, beef and pork, soybeans and soybean foods, fruit, and mushrooms) significantly associated with the ND score. All of these 9 components were weighted and a new weighted JDI (WJDIg) was developed. The $\mathrm{wJDl}_{9}$ score was also positively correlated with the ND score (Spearman's $\rho[95 \% \mathrm{Cl}]=0.61[0.58,0.64]$; $P<0.05)$. However, scores for all 3 indices were positively correlated with sodium intake. The WJDI, score obtained using dietary record data from 2008 to 2010 was also positively correlated with the ND score (Spearman's $\rho[95 \% \mathrm{Cl}]=0.61[0.58,0.64] ; P<0.05)$.

Conclusions-: Adhering to a traditional Japanese diet as defined by the JDI was associated with good ND. Furthermore, the modified indices ( $\mathrm{mJDI}_{12}$ and $\mathrm{wJDl}_{9}$ ) had a higher performance for ND. However, all of the indices were correlated with high sodium intake.
\end{abstract}

Keywords: Japanese diet, Nutrient intake, Nutrient density, Dietary record, Cross-sectional study

\footnotetext{
* Correspondence: zhangshu@med.tohoku.ac.jp

${ }^{\dagger}$ Shu Zhang and Rei Otsuka contributed equally to this work.

'Division of Epidemiology, Department of Health Informatics and Public

Health, Tohoku University School of Public Health, Graduate School of

Medicine, 2-1 Seiryo-machi, Aoba-ku, Sendai, Miyagi 980-8575, Japan

Full list of author information is available at the end of the article
}

(c) The Author(s). 2019 Open Access This article is distributed under the terms of the Creative Commons Attribution 4.0 International License (http://creativecommons.org/licenses/by/4.0/), which permits unrestricted use, distribution, and reproduction in any medium, provided you give appropriate credit to the original author(s) and the source, provide a link to the Creative Commons license, and indicate if changes were made. The Creative Commons Public Domain Dedication waiver (http://creativecommons.org/publicdomain/zero/1.0/) applies to the data made available in this article, unless otherwise stated. 


\section{Background}

Previous studies have reported that a traditional Japanese diet is associated with a lower risk of mortality [1-3] and adverse health outcomes (e.g. disability, dementia, depression) [4-7]. Although such findings have suggested that the traditional Japanese diet well balanced in terms of nutrient intake, the nutritional characteristics of the traditional Japanese diet have remained unclear.

According to the Japanese Diet Index (JDI) [8], 7 adhering components ("rice", "miso soup", "fish and shellfish", "green and yellow vegetables", "seaweed", "pickles", "green tea") and 2 non-adhering components ("beef and pork", "coffee") are considered part of the traditional Japanese diet. In our previous study [4], the JDI was derived by factor analysis (principal component analysis; PCA) and confirmatory factor analysis by using the daily consumption (weight in grams) of 39 food items from the FFQ. Recent studies [9-11] also showed consistency in regard to the food components with the JDI with other typical Japanese dietary patterns derived by PCA or dietary records (DRs).

Our previous simulation study suggested that the JDI is related to better overall nutrient intake [8]. In brief, the JDI score was positively correlated with protein, fiber, vitamins $\mathrm{A}, \mathrm{C}$, and $\mathrm{E}$, calcium, iron, potassium, and magnesium, and negatively correlated with saturated fat and sugar. Nevertheless, our previous study also showed that the JDI score was positively correlated with sodium. Furthermore, similar to the JDI, a previous study using a nationally representative dataset suggested an associations between rice and plant food and fish in the Japanese population [12], although rice (basically white rice) intake has been suggested to be related to a higher risk of diabetes both in Japan and in western countries [13, 14]. To date, except for the traditional Japanese diet, almost no dietary patterns include unhealthy dietary factors (e.g. sodium and refined grains). To investigate the nutritional characteristics of the traditional Japanese diet (which includes unhealthy dietary factors but has beneficial effects on health) would be intriguing and informative.

However, our simulation was based on the non-quantitative food frequency questionnaire method. Therefore, as a limitation, the previous study would have included considerable misclassification of foods and nutrient intakes. Additionally, as another limitation, the places of residence for the population formerly used to generate the JDI and that used in the simulation study are very close geographically, making the external validity of the simulation results still a concern. In other words, the nutritional characteristics of the traditional Japanese diet have not been sufficiently evaluated. A study using a more accurate dietary survey (such as the DR method) has therefore been needed for this purpose.

Additionally, as well as the above 9 components of the JDI, a recent systematic review has reported that several other foods, in particular, "soybeans and soybean foods", "fruit", and "mushrooms", could also be applied as components of the traditional Japanese diet [15]. Therefore, there is also a need to examine the nutritional characteristics of a modified JDI that includes these 3 components.

\section{Methods \\ Aim}

The purpose of the present study was to examine the relationship between adhering to a traditional Japanese diet and nutritional characteristics. Accordingly, based on DR data, we checked the correlations between Japanese diet indices and nutrient density.

\section{Study participants}

This was a cross-sectional study based on data from the fifth wave (July 2006 to July 2008) of the National Institute for Longevity Sciences-Longitudinal Study of Aging (NILS-LSA). Details of the NILS-LSA have been reported elsewhere [16]. In brief, participants in the NILSLSA included randomly selected age- and sex-stratified individuals from a pool of non-institutionalized residents in the NILS neighborhood areas (Obu City, Higashiura Town) in Aichi Prefecture, Japan. The first wave of the NILS-LSA was carried out from November 1997 to April 2000 and involved 2267 participants (1139 men, 1128 women; age range $40-79$ years). The participants were followed up every 2 years. When participants could not be followed up (e.g. if they moved out to the other area, dropped out for personal reasons or died), new age- and sex-matched random samples of the same number of dropout participants were recruited except for participants over 79 years old. The men and women participants aged 40 years were also newly recruited every year. In each wave, a 3-day DR was conducted for dietary assessment. We applied the data from the fifth wave in the present study for two reasons: (1) during this period, the Standard Tables of Foods Composition 2010 was applied for calculation of nutrient and energy intakes [17], and (2) the number of participants who completed the 3-day DR was the largest.

Among subjects who participated in the fifth wave ( $n=2419$, aged 40 years or over), those for whom data for the DR were unavailable were excluded $(n=198)$. Thus, a total of 2221 participants aged between 40 and 88 years were included in the present analysis. 


\section{Dietary assessments}

Dietary intakes were assessed using 3-day DRs. The DR was completed over 3 continuous days (both weekdays and 1 weekend day), and most participants completed it at home and returned records within 1 month. Food was weighed separately on a scale (1-kg kitchen scales; Sekisui Jushi, Tokyo, Japan) before being cooked or portion sizes estimated. Participants also recorded their diet using a disposable camera (27 shots; Fuji Film, Tokyo, Japan) by taking photos of meals before and after eating. Dietitians used these photos to complete missing data, and telephoned participants to resolve any discrepancies or obtain further information when necessary. Averages for 3-day nutrient and energy intakes were calculated according to the Standard Tables of Foods Composition 2010 in Japan and other sources [17].

\section{Japanese diet indices}

In the present study, 3 Japanese diet indices were evaluated. All components of the indices were grouped based on the definitions used in the National Health and $\mathrm{Nu}$ trition Survey 2011 (Japan) [18].

First, according to previous studies [4, 5], we identified the JDI by the following 9 components: "rice", "miso", "fish and shellfish", "green and yellow vegetables", "seaweed", "pickles", "green tea”, "beef and pork", and "coffee". Although previous studies used the item "miso soup" (not "miso"), there was no corresponding definition in the National Health and $\mathrm{Nu}$ trition Survey 2011 (Japan). Therefore, "miso" (a broader definition than miso soup) was applied instead of "miso soup". The item "beef and pork" did not include internal organs. For each of the 7 adhering components ("rice", "miso", "fish and shellfish", "green and yellow vegetables", "seaweed", "pickles", and "green tea"), participants were assigned 1 point if their daily intake was equal to or over the sex-specific median. For each of the 2 non-adhering components ("beef and pork" and "coffee"), participants were assigned 1 point if their daily intake was below the sex-specific median (sex-specific median was calculated using the DR data of all participants). Thus, the JDI score ranged from 0 to 9 . Higher scores indicated greater conformity to the traditional Japanese diet.

Second, referring to a recent review [15], we defined a 12-component modified Japanese Diet Index $\left(\mathrm{mJDI}_{12}\right)$ to which 3 adhering components ("soybeans and soybean foods", "fruit", and "mushrooms") had been added to the JDI. Thus, the mJDI 12 score ranged from 0 to 12 .

Finally, we developed an n-component-weighted Japanese Diet Index $\left(\mathrm{wJDI}_{\mathrm{n}}\right)$ that comprised $n$ selected components which were significantly associated with the nutrient density score from the $\mathrm{mJDI}_{12}$. The component selection was conducted using a multiple linear regression model and each selected component was weighted based on the results of this model.

\section{Nutrient density}

In the present study, "nutrient density" was redefined as the percentage of daily actual intake relative to the Dietary Reference Intake (DRI) for Japanese 2015 [19]. By reference to the Nutrient-rich Foods 9.3 index [20, 21], the densities of 11 nutrients (9 components to encourage: protein, fiber, Vitamin A, Vitamin C, Vitamin E, calcium, iron, potassium, and magnesium; 2 components to limit: saturated fat and sodium) were assessed in the present study. However, our data did not include sugar because DRI for sugar is not listed in the DRIs for Japanese 2015.

The density of each nutrient was calculated using the following equation: nutrient density $=$ daily intake value $\overline{\text { age-sex-specified daily reference value }} \times 100 \%$. Then, each nutrient density was further standardized by the age- and sexspecified recommended daily energy intake value (except for saturated fat). Both the daily reference value for each nutrient and the daily recommended energy intake value were based on the DRIs for Japanese, 2015 (Table 1).

Thus, a nutrient density score was obtained as follows: nutrient density score $=\sum 9$ encouraged nutrient densities $-\sum 2$ limit nutrient densities; (nutrient densities were all energy-standardized except for saturated fat). A higher nutrient density score implies better overall nutrient intake.

\section{Statistical analysis}

First, Spearman's correlation analyses were performed to assess the correlations between the JDI score, the $\mathrm{mJDI}_{12}$ score and the nutrient density score.

Second, three steps were used to define the $\mathrm{wDI}_{\mathrm{n}}$ : (1) because the values of the nutrient density score were not normally distributed (skewness $=1.35$; kurtosis $=3.82$ ), a logarithmic transformation of it was used (skewness $=0.25$; kurtosis $=0.44$ ). Then multiple linear regression model adjusted for energy intake was employed to select $n$ significant associated components of the log nutrient density score, from the 12 components in the $\mathrm{mJDI}_{12} ;(2)$ each selected component was weighted by 10 times its standardized coefficients to obtain an integer point (for the convenience of summing up the JDI score) (standardized coefficient refers to per standard deviation increase in the predictor variable and implies the relative importance of the associations of food components with the log nutrient density score; i.e. the weight); and (3) the wDI $_{n}$ score was summed by the weights of all $n$ selected components. 
Table 1 Daily reference values for individual nutrients and recommended energy intake values ${ }^{\text {a }}$

\begin{tabular}{|c|c|c|c|c|c|}
\hline & Unit & Sex & Daily referen & e value ${ }^{b}$ & \\
\hline & & & $30-49$ years & 50-69 years & $\geq 70$ years \\
\hline Energy & kcal & Female & 2000 & 1900 & 1750 \\
\hline & & Male & 2650 & 2450 & 2200 \\
\hline Protein & g & Female & 50 & 50 & 50 \\
\hline & & Male & 60 & 60 & 60 \\
\hline Fiber & g & Female & 18 & 18 & 17 \\
\hline & & Male & 20 & 20 & 19 \\
\hline Vitamin $A^{c}$ & $\mu \mathrm{g}$ & Female & 700 & 700 & 650 \\
\hline & & Male & 900 & 850 & 800 \\
\hline Vitamin C & $\mathrm{mg}$ & Female & 100 & 100 & 100 \\
\hline & & Male & 100 & 100 & 100 \\
\hline Vitamin $\mathrm{E}^{\mathrm{d}}$ & $\mathrm{mg}$ & Female & 6.0 & 6.0 & 6.0 \\
\hline & & Male & 6.5 & 6.5 & 6.5 \\
\hline Calcium & $\mathrm{mg}$ & Female & 650 & 650 & 650 \\
\hline & & Male & 650 & 700 & 700 \\
\hline Iron & $\mathrm{mg}$ & Female & 6.5 & 6.5 & 6.0 \\
\hline & & Male & 7.5 & 7.5 & 7.0 \\
\hline Potassium & $\mathrm{mg}$ & Female & $\geq 2600$ & $\geq 2600$ & $\geq 2600$ \\
\hline & & Male & $\geq 3000$ & $\geq 3000$ & $\geq 3000$ \\
\hline Magnesium & $\mathrm{mg}$ & Female & 290 & 290 & 270 \\
\hline & & Male & 370 & 350 & 320 \\
\hline Sodium ${ }^{e}$ & $\mathrm{mg}$ & Female & $\leq 2800$ & $\leq 2800$ & $\leq 2800$ \\
\hline & & Male & $\leq 3200$ & $\leq 3200$ & $\leq 3200$ \\
\hline Saturated fat ${ }^{f}$ & $g$ & Female & $<15.6$ & $<14.8$ & $<13.6$ \\
\hline & & Male & $<20.6$ & $<19.1$ & $<17.1$ \\
\hline
\end{tabular}

${ }^{\mathrm{a}}$ Guided by the Dietary Reference Intakes for Japanese, 2015

${ }^{\mathrm{b}}$ Based on the Recommended Dietary Allowance (RDA). For nutrients with unavailable RDA data, the Estimated Average Requirement (EAR) or the Tentative Dietary Goal (DG) was applied

'Retinol equivalent

${ }^{\mathrm{d}}$ Tocopherol equivalent

eDaily reference values for salt intake are " $\leq 7 \mathrm{~g}$ for female" and " $\leq 8 \mathrm{~g}$ for male". Thus, we converted salt to sodium: Sodium $(\mathrm{mg})=$ daily reference value for salt intake $(\mathrm{g}) \times[600(\mathrm{mg}) / 1.5(\mathrm{~g})]$

fDaily reference value for saturated fat is " $<7 \%$ of energy intake". Thus, we converted saturated fat intake to volume based on "energy of saturated fatty acid $=9 \mathrm{kcal} / \mathrm{g}^{\prime}$ : Saturated fat $(\mathrm{g})=$ daily reference value for energy intake (kcal) $\times 7 \% / 9(\mathrm{kcal} / \mathrm{g})$

Third, Spearman's correlation analysis was conducted to assess the correlation between the wJDI ${ }_{n}$ score and the nutrient density score.

To test the significance of the difference between above Spearman's correlation coefficients (i.e. Spearman's correlation coefficients between the JDI score, the $\mathrm{mJDI}_{12}$ score, the wJDI ${ }_{\mathrm{n}}$ score and the nutrient density score), we calculated values of $z$ for JDI, $\mathrm{mJDI}_{12}$, and $\mathrm{wJDI}_{\mathrm{n}}$, respectively, were calculated as follows: $\mathrm{z}=1.151$
$3 \times \lg \frac{1+\rho}{1-\rho}$; where $\rho$ means the Spearman's correlation coefficients between the JDI score, the $\mathrm{mJDI}_{12}$ score, the wJDI $I_{n}$ score and the nutrient density score. Then $S_{\left(z_{1}-z_{2}\right)}$ $=\sqrt{\frac{1}{n_{1}-3}+\frac{1}{n_{2}-3}}$ was calculated; in a same survey wave, $\mathrm{n}_{1}=\mathrm{n}_{2}=\mathrm{n}$, so $\mathrm{S}_{\left(\mathrm{z}_{1}-\mathrm{z}_{2}\right)}=\sqrt{\frac{2}{n_{1}-3}}$. Finally, $\mathrm{U}_{\left(\mathrm{z}_{1}, \mathrm{z}_{2}\right)}=\frac{z_{1}-z_{2}}{\mathrm{~S}_{\left(\mathrm{z}_{1}-z_{2}\right)}}$ was calculated; if $\mathrm{U}_{\left(\mathrm{z}_{1}, \mathrm{z}_{2}\right)}>1.96$ or $<-1.96$, then $P<0.05$; otherwise $P \geq 0.05$. To consider an external validity, we also assessed the correlation between the JDIs score, and between the $\mathrm{wDII}_{\mathrm{n}}$ and the nutrient density score using other period data (the sixth wave survey of the NILSLSA; July 2008 to July 2010) $(n=2115)$.

Finally, the Spearman's correlation was applied to assess the correlations between the 3 Japanese Diet indices scores and the 11 nutrient intakes, respectively. Energyadjusted correlations were also checked by the residual method [22].

All data were analyzed using Statistical Analysis System (SAS) version 9.3 (SAS Institute, Cary, NC, USA). All statistical tests described here were twosided, and differences at $P<0.05$ were accepted as significant.

\section{Results \\ Characteristics of participants}

Our participants comprised 1104 men (49.7\%) and 1117 women (50.3\%), with a mean (SD) age of 60.7 (12.4) years.

$J \mathrm{DI}, \mathrm{mJDI}_{12}$ and nutrient density score

The correlations between the JDI score, the $\mathrm{mJDI}_{12}$ score and the nutrient density score are shown in Fig. 1 and Fig. 2, respectively. Both the JDI score and the $\mathrm{mJDI}_{12}$ score were positively correlated with the nutrient density score (Spearman's $\rho$ [95\% CI], 0.34 [0.31, 0.38] for JDI score and $0.44[0.41,0.48]$ for $\mathrm{mJDI}_{12}$ score; both $P<0.05)$, the correlation was stronger for the $\mathrm{mJDI}_{12}$ score $(z=3.94, P<0.05)$.

\section{Individual components of the $\mathrm{mJDI}_{12}$ and nutrient density score}

The associations between individual components of the $\mathrm{mJDI}_{12}$ and nutrient density score are shown in Table 2 . Nine components, except for miso, pickles, and coffee, were significantly correlated with the nutrient density score. Therefore, the wJDI ${ }_{n}$ was defined as the wJDI 9 (9component weighted Japanese Diet Index). Since the standardized coefficients for "green and yellow vegetables" (0.3), "fruit" (0.2) and "soybeans and soybean foods" (0.2) were higher, and the standardized coefficient

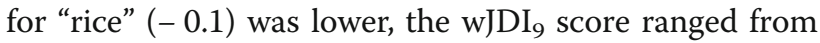
-1 to 12 (Additional file 1 Table S1). 


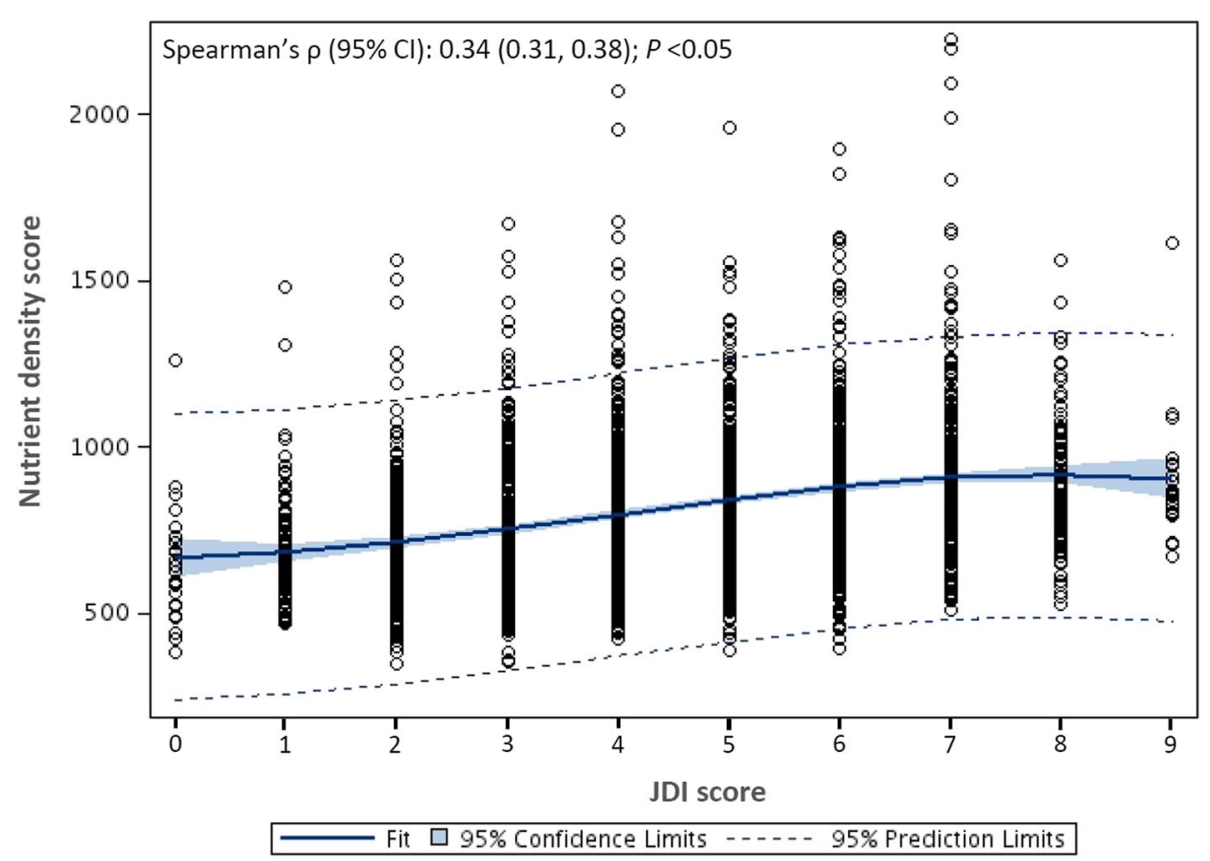

Fig. 1 Correlation between the original 9-component Japanese Diet Index score (JDI) and the nutrient density score

\section{wJDI $_{9}$ and nutrient density score}

The correlation between the $\mathrm{wDI}_{9}$ score and the nutrient density score is shown in Fig. 3. The $\mathrm{wDI}_{9}$ score was positively correlated with the nutrient density score (Spearman's $\rho[95 \% \mathrm{CI}]=0.61[0.58,0.64] ; P<0.05)$. This correlation coefficient significantly differed from those of the JDI (Spearman's $\rho[95 \% \mathrm{CI}]=0.34[0.31,0.38]$ ) or the $\mathrm{m} J D I_{12}$ (Spearman's $\rho[95 \% \mathrm{CI}]=0.44[0.41,0.48]$ ) ( $z=11.8$ and 7.9, respectively; $P<0.05$ for both).

Even when same analyses were applied with another data (the sixth wave survey of the NILS-LSA; $n=2115$ ), almost same result correlation between the

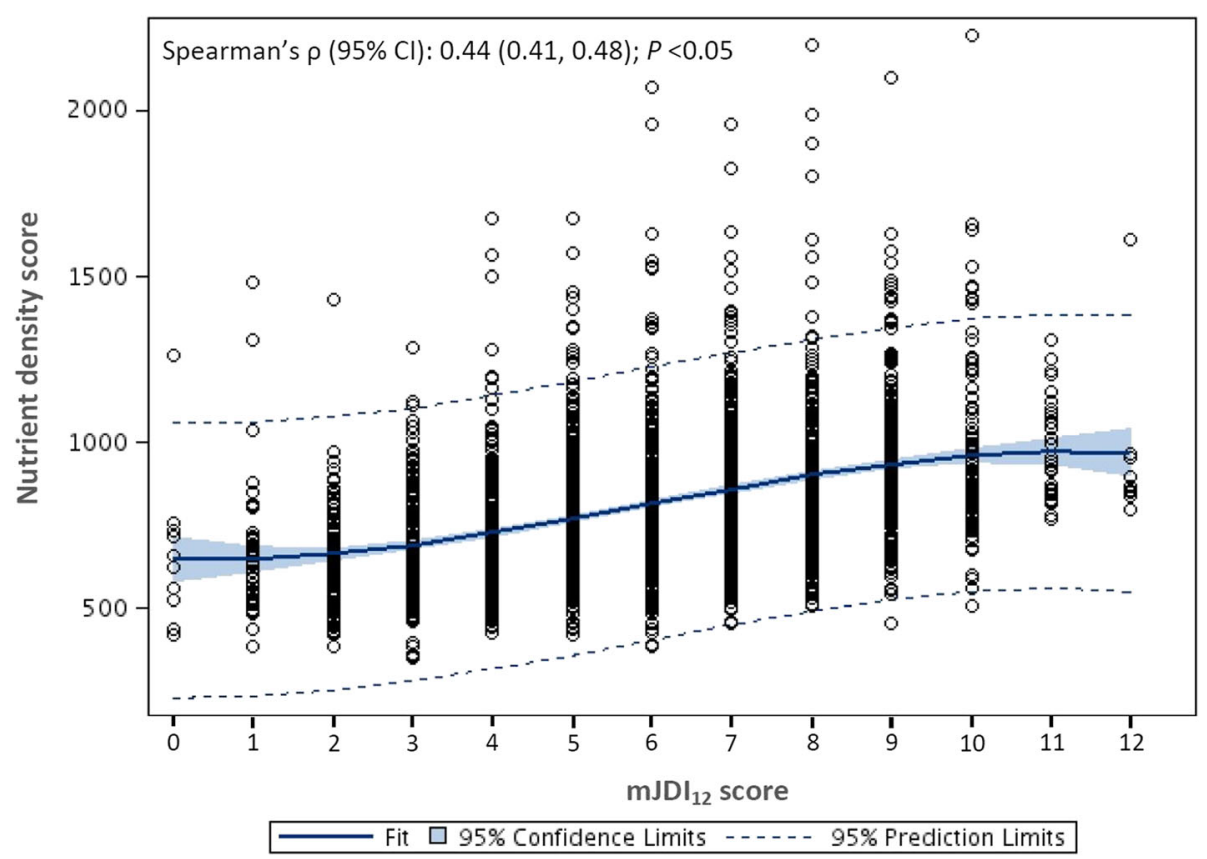

Fig. 2 Correlation between the 12-component modified Japanese Diet Index score $\left(\mathrm{mJDI}_{12}\right)$ and the nutrient density score 
Table 2 Associations between the components of the 12-component modified Japanese Diet Index $\left(\mathrm{mJDI}_{12}\right)$ and the log nutrient density score $(n=2221)$

\begin{tabular}{|c|c|c|c|c|}
\hline & $\beta^{b}$ & $\mathrm{SE}^{\mathrm{c}}$ & $P$-value & Standardized $\beta^{d}$ \\
\hline \multicolumn{5}{|c|}{ Food components of the $\mathrm{mJDI}_{12}$ (Dummy variable) $^{a}$} \\
\hline Rice & -0.07 & 0.010 & $<0.001$ & -0.1 \\
\hline Miso & 0.01 & 0.010 & 0.444 & - \\
\hline Fish and shellfish & 0.04 & 0.009 & $<0.001$ & 0.1 \\
\hline Green and yellow vegetables & 0.18 & 0.009 & $<0.001$ & 0.3 \\
\hline Seaweeds & 0.05 & 0.009 & $<0.001$ & 0.1 \\
\hline Pickles & 0.00 & 0.009 & 0.863 & - \\
\hline Green tea & 0.07 & 0.009 & $<0.001$ & 0.1 \\
\hline Beef and pork & 0.05 & 0.009 & $<0.001$ & 0.1 \\
\hline Coffee & 0.01 & 0.009 & 0.437 & - \\
\hline Soybeans and soybean foods & 0.08 & 0.009 & $<0.001$ & 0.2 \\
\hline Fruit & 0.11 & 0.009 & $<0.001$ & 0.2 \\
\hline Mushrooms & 0.04 & 0.009 & $<0.001$ & 0.1 \\
\hline Energy (kcal) & -0.00005 & 0.00001 & $<0.001$ & \\
\hline
\end{tabular}

${ }^{a}$ Dummy variable: 0 points (reference) vs. 1 point. 0 points: daily intake <sex-specific median for rice, miso, fish and shellfish, green and yellow vegetables, seaweed, pickles, green tea, soybeans and soybean foods, fruit, and mushrooms, and daily intake $\geq$ sex-specific median for beef and pork, and coffee; 1 point: otherwise

${ }^{b}$ Non-standardized regression coefficient (i.e. the expected change in the log nutrient density score when the JDI score for one food component increases from 0 to 1 while the others remain fixed)

'Standard error of the non-standardized regression coefficient $\beta$ (i.e. an indication of how much the point estimated $\beta$ is likely to vary from the corresponding population parameter)

${ }^{\mathrm{d}}$ Standardized regression coefficient (referring to per standard deviation increase in the predictor variable and implying the relative importance of the relationship of food components with the log nutrient density score; i.e. the weight). Only standardized $\beta$ values for food components with $P<0.05$ are listed

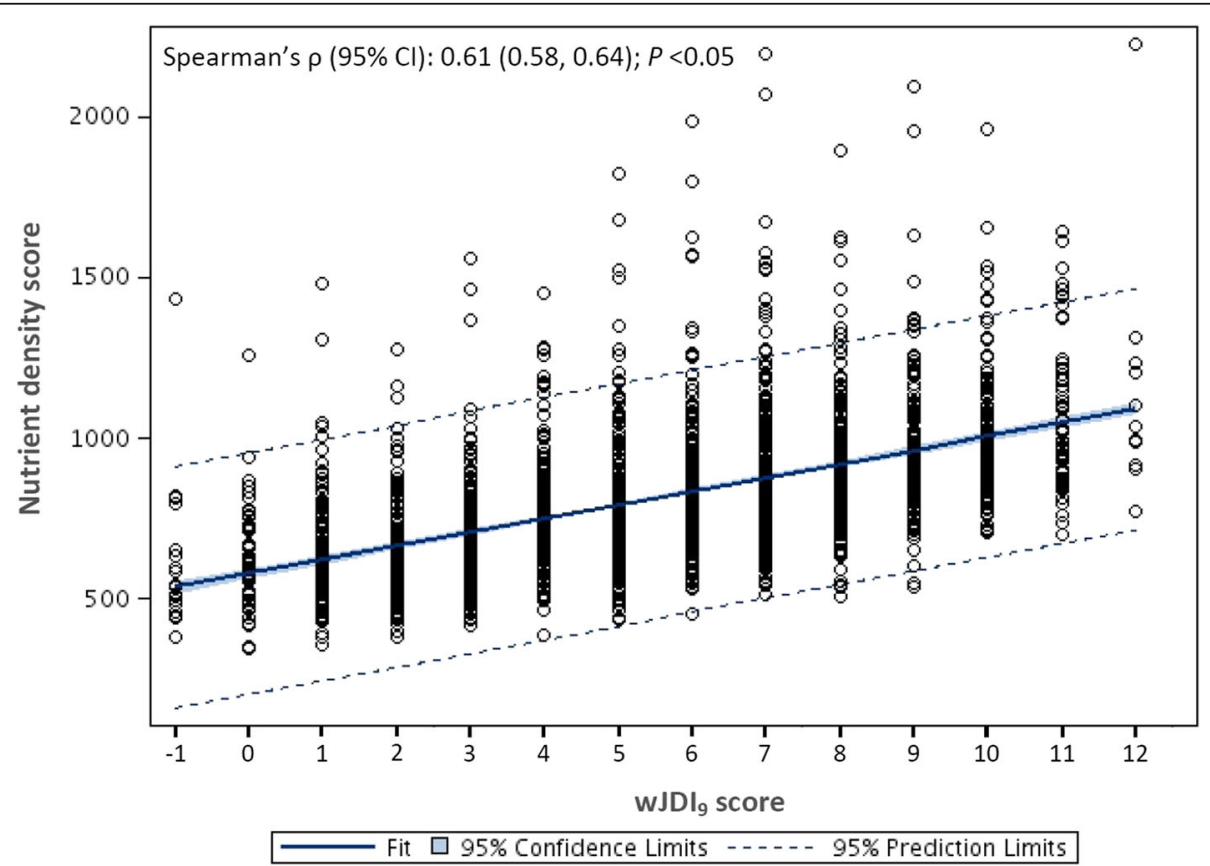

Fig. 3 Correlation between the 9-component weighted Japanese Diet Index score (WJDIg) and the nutrient density score 
$\mathrm{wJDI}_{9}$ score and the nutrient density score was observed (Additional file 2 Fig. S1; Spearman's $\rho$ [95\% $\mathrm{CI}]=0.61[0.58,0.64] ; P<0.05)$. This correlation coefficient was also significantly different from that of the JDI (Spearman's $\rho[95 \% \mathrm{CI}]=0.35[0.31,0.39]$ ) or the $\mathrm{mJDI}_{12}$ (Spearman's $\rho\left[\begin{array}{lll}95 \% & \mathrm{CI}\end{array}\right]=0.44 \quad[0.41$, $0.48])(\mathrm{z}=11.2$ and 7.7 , respectively; $P<0.05$ for both).

\section{$J \mathrm{JI}, \mathrm{mJDI}_{12}, \mathrm{wJDI}_{9}$ score and nutrient intakes}

The correlations between the JDI, $\mathrm{mJDI}_{12}, \mathrm{wJDI}_{9}$ score and nutrient intakes (components of the nutrient density score) are shown in Table 3. In the energy-adjusted results, all of the scores for these 3 indices were positively correlated with the intakes of all 9 encouraged nutrients (range of Spearman's $\rho$, $0.15-0.49$ for the JDI, $0.21-0.55$ for the $\mathrm{mJDI}_{12}, 0.36-$ 0.66 for the $\mathrm{wJDI}_{9}$ ), and negatively correlated with saturated fat intake (corresponding Spearman's $\rho$, $0.35,-0.32$, and -0.16 , respectively). However, the scores for all of these 3 indices were positively correlated with sodium intake (corresponding Spearman's $\rho, 0.38,0.38$, and 0.26 , respectively). All of the above correlations were statistically significant $(P<0.05)$.

Median values for nutrient intakes according to the tertiles of the JDI, $\mathrm{mJDI}_{12}$, and $\mathrm{wJDI}_{9}$ are shown in
Additional file 1 Table S2, the associations between scores and nutrient intakes were similar to those in Table 3.

\section{Discussion}

The purpose of the present study was to examine the relationship between adhering to a traditional Japanese diet and nutrient density. Based on data from a DR survey of a large sample $(n=2221)$, correlations between the scores for 3 Japanese diet indices (JDI, $\mathrm{mJDI}_{12}$, $\mathrm{wJDI}_{9}$ ) and nutrient density were investigated. A higher JDI score was shown to be correlated with a higher nutrient density score.

The positive correlation between the $\mathrm{mJDI}_{12}$ ( 3 food components, i.e. "soybeans and soybean foods", "fruit", and "mushrooms", added to the JDI) score and the nutrient density score was stronger than that for the JDI. Additionally, the positive correlation between the wJDI ${ }_{9}$ score (summed by weighted points for 9 selected components, excluding "miso", "pickles", and "coffee" from the $\mathrm{mJDI}_{12}$ ) and the nutrient density score was stronger than that for the $\mathrm{mJDI}_{12}$ (corresponding Spearman's $\rho$, 0.61 vs. 0.44 ). These results suggest that the $\mathrm{mJDI}_{12}$ or the $\mathrm{wJDI}_{9}$ is more useful for defining better overall nutrient intakes than the JDI. For each nutrient component of the nutrient density score, intakes of magnesium, potassium, fiber and calcium were better according to the

Table 3 Correlations between JDI, $\mathrm{JJDI}_{12}, \mathrm{wJDl}_{9}$ score $^{\mathrm{a}}$ and nutrient intakes $(\mathrm{n}=2221)$

\begin{tabular}{|c|c|c|c|c|c|c|c|c|c|c|c|c|}
\hline \multirow[b]{3}{*}{ Energy (kcal) } & \multicolumn{6}{|l|}{ Crude } & \multicolumn{6}{|c|}{ Energy-adjusted } \\
\hline & \multicolumn{2}{|l|}{$\overline{\mathrm{JDI}}$} & \multicolumn{2}{|c|}{$\mathrm{mJDI}_{12}$} & \multicolumn{2}{|l|}{ wJDl 9} & \multicolumn{2}{|l|}{$\overline{J D I}$} & \multicolumn{2}{|l|}{$\mathrm{mJDI}_{12}$} & \multicolumn{2}{|l|}{$\mathrm{WJDl}_{9}$} \\
\hline & 0.09 & $(0.05,0.13)$ & 0.12 & $(0.08,0.16)$ & 0.06 & $(0.02,0.10)$ & & & & & & \\
\hline Protein (g) & 0.23 & $(0.19,0.27)$ & 0.28 & $(0.24,0.32)$ & 0.26 & $(0.22,0.30)$ & 0.26 & $(0.22,0.30)$ & 0.31 & $(0.27,0.35)$ & 0.36 & $(0.32,0.40)$ \\
\hline Fiber (g) & 0.42 & $(0.39,0.46)$ & 0.55 & $(0.51,0.58)$ & 0.63 & $(0.60,0.65)$ & 0.42 & $(0.38,0.45)$ & 0.54 & $(0.50,0.57)$ & 0.65 & $(0.62,0.67)$ \\
\hline Vitamin A $(\mu \mathrm{g})$ & 0.28 & $(0.24,0.32)$ & 0.35 & $(0.31,0.39)$ & 0.45 & $(0.41,0.48)$ & 0.25 & $(0.21,0.29)$ & 0.31 & $(0.27,0.35)$ & 0.43 & $(0.39,0.47)$ \\
\hline Vitamin C (mg) & 0.34 & $(0.30,0.38)$ & 0.42 & $(0.39,0.46)$ & 0.49 & $(0.45,0.52)$ & 0.31 & $(0.27,0.34)$ & 0.38 & $(0.34,0.42)$ & 0.46 & $(0.43,0.50)$ \\
\hline Vitamin E (mg) & 0.18 & $(0.14,0.22)$ & 0.25 & $(0.21,0.29)$ & 0.38 & $(0.34,0.42)$ & 0.15 & $(0.11,0.19)$ & 0.21 & $(0.17,0.25)$ & 0.41 & $(0.37,0.45)$ \\
\hline Calcium (mg) & 0.26 & $(0.22,0.30)$ & 0.34 & $(0.30,0.38)$ & 0.43 & $(0.40,0.47)$ & 0.23 & $(0.19,0.27)$ & 0.31 & $(0.27,0.35)$ & 0.44 & $(0.40,0.47)$ \\
\hline Iron (mg) & 0.46 & $(0.43,0.50)$ & 0.53 & $(0.50,0.56)$ & 0.50 & $(0.47,0.53)$ & 0.49 & $(0.45,0.52)$ & 0.55 & $(0.52,0.59)$ & 0.56 & $(0.52,0.59)$ \\
\hline Potassium (mg) & 0.37 & $(0.33,0.41)$ & 0.49 & $(0.45,0.52)$ & 0.60 & $(0.57,0.62)$ & 0.38 & $(0.34,0.41)$ & 0.49 & $(0.46,0.53)$ & 0.66 & $(0.64,0.69)$ \\
\hline Magnesium (mg) & 0.39 & $(0.35,0.43)$ & 0.49 & $(0.46,0.52)$ & 0.54 & $(0.51,0.57)$ & 0.42 & $(0.39,0.46)$ & 0.53 & $(0.50,0.56)$ & 0.64 & $(0.62,0.67)$ \\
\hline Sodium (mg) & 0.36 & $(0.33,0.40)$ & 0.37 & $(0.34,0.41)$ & 0.25 & $(0.21,0.29)$ & 0.38 & $(0.35,0.42)$ & 0.38 & $(0.34,0.41)$ & 0.26 & $(0.22,0.30)$ \\
\hline Saturated fat (g) & -0.23 & $\begin{array}{l}(-0.27 \\
-0.19)\end{array}$ & -0.19 & $\begin{array}{l}(-0.23 \\
-0.15)\end{array}$ & -0.09 & $\begin{array}{l}(-0.14 \\
-0.05)\end{array}$ & -0.35 & $\begin{array}{l}(-0.39 \\
-0.31)\end{array}$ & -0.32 & $\begin{array}{l}(-0.36 \\
-0.28)\end{array}$ & -0.16 & $\begin{array}{l}(-0.20 \\
-0.12)\end{array}$ \\
\hline $\begin{array}{l}\text { Saturated fatty acid, } \\
\%^{c}\end{array}$ & -0.17 & $\begin{array}{l}(-0.21,- \\
0.12)\end{array}$ & -0.15 & $\begin{array}{l}(-0.19,- \\
0.11)\end{array}$ & -0.07 & $\begin{array}{l}(-0.11,- \\
0.03)\end{array}$ & & & & & & \\
\hline Sodium / Potassium & -0.03 & $(-0.07,0.01)$ & $\begin{array}{l}- \\
0.15\end{array}$ & $\begin{array}{l}(-0.19,- \\
0.10)\end{array}$ & -0.38 & $\begin{array}{l}(-0.42,- \\
0.34)\end{array}$ & & & & & & \\
\hline
\end{tabular}

aJDI, Japanese Diet Index (original 9-component Japanese Diet Index); $\mathrm{mJDI}_{12}$, 12-component modified Japanese Diet Index; wJDI, 9-component weighted Japanese Diet Index; $\mathrm{Cl}$, confidence interval

${ }^{\mathrm{b}}$ Components of the nutrient density score: 9 encouraged nutrients (protein, fiber, vitamin A, vitamin C, vitamin E, calcium, iron, potassium, magnesium) and 2 limited nutrients (sodium, saturated fat)

'Saturated fatty acid $(\mathrm{g}) /$ all fatty acid $(\mathrm{g}) \times 100 \%$ 
$\mathrm{mJDI}_{12}$ than according to the JDI. Because soybeans and soybean foods [23], fruit [24], and mushrooms [25] are known to be resources of these nutrients, these food components would have contributed to improving the nutrient intakes.

However, the scores for all 3 indices were positively correlated with the intake of sodium, being consistent with a previous study [8]. After excluding "miso" and "pickles" (which are known to have a high salt content) from the $\mathrm{mJDI}_{12}$, although the correlation between the $\mathrm{wJDI}_{9}$ score and sodium intake became weaker, a considerable correlation remained. A previous study has reported that seasonings such as soy sauce and salt are the major sources contributing to total sodium intake in Japan [26]. In the present study, seasonings were also ranked in the top 3 (Additional file 1 Table S4). On the other hand, scores for all 3 indices were positively correlated with potassium intake, and inversely correlated with the sodium/potassium ratio (especially for the $\mathrm{wJDI}_{9}$ ), also being consistent with the previous study [8]. Thus, for the traditional Japanese diet, a high potassium intake might offset the demerit of high sodium intake.

Based on the association between each component of the $\mathrm{mJDI}_{12}$ and the nutrient density score, we developed a weighted index, the "wJDI,", which encourages a higher intake of "green and yellow vegetables", "soybeans and soybean foods" and "fruit", and a lower intake of "rice" (even the traditional Japanese diet is commonly thought to be rice-centered). The previous study had suggested that a dietary pattern with similar weights contributed to higher overall nutrient adequacy and lower oxidative stress [8]. Another study has also indicated that a Japanese food score that did not encourage rice intake was related to lower cardiovascular disease mortality [1]. These findings suggest that, although rice is a staple food in Japan, a diet that includes excessive and single intake of rice may not be desirable. As a post hoc analysis, we checked food intake volumes among better cases (participants who were in both the top 25\% for nutrient density score and top $25 \%$ for the $\mathrm{wJDI}_{9}$ score) (Additional file 1 Table S3). As a result, the mean daily intake volume of "rice" was $278 \mathrm{~g}$ (mean daily total energy intake, $2013 \mathrm{kcal}$ ), being rather lower than that for the Japanese population as a whole (corresponding values, $317 \mathrm{~g}$ for the $50-59$-year age group [1916 kcal], $310 \mathrm{~g}$ for the $60-69$-year age group [1892 kcal], and 323 $\mathrm{g}$ for the $\geq 70$-year age group [1745 kcal]) [18].

It has often been assumed that the traditional Japanese diet is a lean diet such as that of Buddhist cuisine (shojin-ryori in Japanese), which might contribute to the prevention of obesity [27]. On the other hand, a lean diet (which is usually inadequately defined in terms of nutrient and food content, and contains less red meat and fat) might also contribute to undernutrition [28]. However, since all indices were related to sufficient intakes of energy and protein (Table 3 and Additional file 1 Table S2), the traditional Japanese diet as defined in the present study may not contribute to a high risk of undernutrition.

Indices have been proven to be useful in epidemiological studies and to develop and apply nutritional strategies [29] and some dietary indices (such as the healthy eating index and Mediterranean diet index) have been widely applied in western populations. Given the specific situation of diet intake in Japan (a comparable lower total calorie intake, a different Protein-Fat-Carbohydrate balance, and a different fatty acid ratio compared with western countries [30-33]), development, modification, and application of the JDI may be important for public health promotion for the Japanese population. However, it is still worth noting that, among the practical aspects of our finding, comprehensive health consultation and guidance should be conducted involving other lifestyle behaviors (e.g. physical activity), socioeconomic context (e.g. sociocultural habits, religious beliefs), food access (e.g. food handling, preparation and storage, purchase of seasonal and local foods,) and so on [34].

This study had several limitations. First, as a general limitation of the DR method, a certain number of subjects might have reported foods that are considered healthier and more socially desirable than what they usually eat [35]. However, since we focused on the dietary pattern (e.g. combinations of food intake), this potential pitfall may not have had a significant impact on our findings. Second, because the DR method is dependent on food composition databases, nutrient intake might have been misclassified in the present study. For example, participants who were conscious of their salt intake might have been more likely to select low-salt versions of some foods that are generally considered to be high in salt (e.g. miso, pickles). If the present study included a substantial fraction of such individuals, then the absolute sodium intake volume and the subsequent correlation between the Japanese Diet Indices score and sodium intake might have been overestimated. Third, although participants used for validation (2008-2010) were not totally the same as those used for the main analyses (2006-2008), they were collected from the same region. Additionally, the National Health and Nutrition Surveys in 2006 [36] and 2017 [37] indicated that the average consumption of "fish and shellfish", and "green and yellow vegetables" decreased, and the average consumption of "beef and pork" increased during the recent 10 years (the Westernization of the Japanese diet [38]). Thus, the average higher consumption of these food components by our participants would represent a relatively traditional Japanese diet in Japan. A further validation study would be needed with participants in a 
different context. Finally, the associations between JDIs and biomarkers were not assessed in the present study. It would be informative to investigate this issue in the future to confirm the nutritional characteristics of the traditional Japanese diet.

\section{Conclusions}

Adhering to a traditional Japanese diet as defined by the JDI was associated with good nutrient density. Furthermore, the modified indices $\left(\mathrm{mJDI}_{12}\right.$ and $\left.\mathrm{wJDI}_{9}\right)$ had higher performance in terms of nutrient density. However, as a demerit, these indices were correlated with high sodium intake.

\section{Additional files}

Additional file 1: Table S1. Points for calculation of the 9-component weighted Japanese Diet index ( $\left(\mathrm{WJD} \mathrm{I}_{9}\right)$. Table S2. Nutrient intakes according to JDI, $\mathrm{mJDI}_{12}, \mathrm{wJDI}_{9}$ score $(n=2221)$. Table S3. Food intakes among the better cases $(n=315)$. Table S4. Percentage of sodium intake from each food in the total diet $(n=2221)$. (DOCX $47 \mathrm{~kb})$

Additional file 2: Figure S1. Correlation between the 9-component weighted Japanese Diet Index score ( $\left.\mathrm{WJDl}_{9}\right)$ and the nutrient density score (applied with the sixth wave survey of the NILS-LSA; $n=2115$. (PDF $263 \mathrm{~kb})$

\section{Abbreviations}

JDI: Japanese diet index; mJDI 12 : 12-component modified index; NILSLSA: National Institute for longevity sciences-longitudinal study of aging; WJDI9: weighted Japanese diet index

\section{Acknowledgments}

We would like to thank Tsuyoshi Tsuduki, Yoshiko Nakata, Mami Takahashi, and Saho Abe for their technical assistance. Permission for publication has been received from all people named in the acknowledgments.

\section{Authors' contributions}

$\mathrm{RO}$ and $\mathrm{HS}$ designed the research; $\mathrm{RO}$ and $\mathrm{HS}$ conducted the research; $\mathrm{SZ}, \mathrm{RO}, \mathrm{YT}$ and $\mathrm{SM}$ analyzed the data; $\mathrm{SZ}, \mathrm{RO}$, and $\mathrm{YT}$ wrote the manuscript; HS, CT, MT, YN, SM and IT gave constructive suggestions; SZ and $\mathrm{RO}$ had primary responsibility for the final content. All authors read and approved the final manuscript.

\section{Funding}

This study was supported by the NARO Bio-oriented Technology Research Advancement Institution (advanced integration research for agriculture and interdisciplinary fields; grant number 17943029) and research funding for Longevity Sciences from the National Center for Geriatrics and Gerontology, Japan (grant number 28-40). None of the funding organizations or sponsors was involved in the study design; in the collection, analysis, or interpretation of data; in writing the report; and in making the decision to submit the article for publication.

\section{Availability of data and materials}

The data that support the findings of this study are available from the National Institute for Longevity Sciences-Longitudinal Study of Aging (NILSLSA) but restrictions apply to the availability of these data, which were used under license for the current study, and so are not publicly available. Data are however available from the authors upon reasonable request and with permission of the NILS-LSA.

\section{Ethics approval and consent to participate}

The protocol for the NILS-LSA study was approved by the Committee for Ethics in Human Research of the National Center for Geriatrics and Gerontology (No. 899-3). All participants are fully informed of the following items. Only subjects who understand and accept examination procedures, and sign their names to a written form to participate in the study (informed consent) are included. This informed consent includes; (1) purpose of the study; (2) detailed procedures for each examination; (3) predictable danger; (4) participation in the examinations totally depends on free will, without any enforcement, and refusal to participate has no disadvantage; (5) to keep secret personal data from the examination. For the utilization of NILS-LSA data in the present collaborative study, the protocol was approved by both the Committee for Ethics in Human Research of the National Center for Geriatrics and Gerontology (No. 1136) and the Ethics Committee of Tohoku University Graduate School of Medicine (Sendai, Japan) (No. 2017-1-988). According to the protocol regarding data utilization, all analyses were performed at the National Center for Geriatrics and Gerontology.

\section{Consent for publication}

Not applicable.

\section{Competing interests}

The authors declare that they have no competing interests.

\section{Author details}

'Division of Epidemiology, Department of Health Informatics and Public Health, Tohoku University School of Public Health, Graduate School of Medicine, 2-1 Seiryo-machi, Aoba-ku, Sendai, Miyagi 980-8575, Japan.

${ }^{2}$ Section of NILS-LSA, National Center for Geriatrics and Gerontology, 7-430 Morioka-cho, Obu City, Aichi 474-8511, Japan. ${ }^{3}$ Institute of Health and Nutrition, Nagoya University of Arts and Sciences, Takeno-yama 57 Iwasaki-cho, Nisshin City, Aichi 470-0196, Japan. ${ }^{4}$ Department of Epidemiology of Aging, National Center for Geriatrics and Gerontology, Obu City, Aichi 474-8511, Japan.

Received: 14 February 2019 Accepted: 19 July 2019

Published online: 30 July 2019

\section{References}

1. Okada E, Nakamura K, Ukawa S, Wakai K, Date C, Iso H, Tamakoshi A. The Japanese food score and risk of all-cause, CVD and cancer mortality: the Japan collaborative cohort study. Br J Nutr. 2018;120:464-71.

2. Shimazu T, Kuriyama S, Hozawa A, Ohmori K, Sato Y, Nakaya N, Nishino Y, Tsubono Y, Tsuji I. Dietary patterns and cardiovascular disease mortality in Japan: a prospective cohort study. Int J Epidemiol. 2007;36:600-9.

3. Abe S, Zhang S, Tomata Y, Tsuduki T, Sugawara Y, Tsuji I. Japanese diet and survival time: the Ohsaki cohort 1994 study. Clin Nutr. 2019.

4. Tomata Y, Watanabe T, Sugawara Y, Chou WT, Kakizaki M, Tsuji I. Dietary patterns and incident functional disability in elderly Japanese: the Ohsaki cohort 2006 study. J Gerontol A Biol Sci Med Sci. 2014;69:843-51.

5. Tomata Y, Sugiyama K, Kaiho Y, Honkura K, Watanabe T, Zhang S, Sugawara $Y$, Tsuji I. Dietary patterns and incident dementia in elderly Japanese: the Ohsaki cohort 2006 study. J Gerontol A Biol Sci Med Sci. 2016;71:1322-8.

6. Suzuki T, Miyaki K, Tsutsumi A, Hashimoto H, Kawakami N, Takahashi M, Shimazu A, Inoue A, Kurioka S, Kakehashi M, et al. Japanese dietary pattern consistently relates to low depressive symptoms and it is modified by job strain and worksite supports. J Affect Disord. 2013;150:490-8.

7. Zhang S, Tomata Y, Sugawara Y, Tsuduki T, Tsuji I. The Japanese Dietary Pattern Is Associated with Longer Disability-Free Survival Time in the General Elderly Population in the Ohsaki Cohort 2006 Study. The Journal of Nutrition. 149(7):2019, 1245-1251.

8. Tomata Y, Zhang S, Kaiho Y, Tanji F, Sugawara Y, Tsuji I. Nutritional characteristics of the Japanese diet: a cross-sectional study of the correlation between Japanese diet index and nutrient intake among community-based elderly Japanese. Nutrition. 2018;57:115-21.

9. Okubo H, Murakami K, Sasaki S, Kim MK, Hirota N, Notsu A, Fukui M, Date C. Relative validity of dietary patterns derived from a self-administered diet history questionnaire using factor analysis among Japanese adults. Public Health Nutr. 2010;13:1080-9.

10. Nanri A, Shimazu T, Ishihara J, Takachi R, Mizoue T, Inoue M, Tsugane S. Reproducibility and validity of dietary patterns assessed by a food frequency questionnaire used in the 5-year follow-up survey of the Japan public health center-based prospective study. J Epidemiol. 2012;22:205-15. 
11. Murakami K, Shinozaki N, Fujiwara A, Yuan X, Hashimoto A, Fujihashi H, Wang $\mathrm{H}-\mathrm{C}$, Livingstone MBE, Sasaki S. A systematic review of principal component analysis-derived dietary patterns in Japanese adults: are major dietary patterns reproducible within a country? Adv Nutr. 2019:10:237-49.

12. Imamura F, Micha R, Khatibzadeh S, Fahimi S, Shi P, Powles J, Mozaffarian D, Global burden of diseases N, chronic diseases expert G. Dietary quality among men and women in 187 countries in 1990 and 2010: a systematic assessment. Lancet Glob Health. 2015:3:e132-42.

13. Nanri A, Mizoue T, Noda M, Takahashi Y, Kato M, Inoue M, Tsugane S, Japan public health center-based prospective study G. Rice intake and type 2 diabetes in Japanese men and women: the Japan public health centerbased prospective study. Am J Clin Nutr. 2010;92:1468-77.

14. Hu EA, Pan A, Malik V, Sun Q. White rice consumption and risk of type 2 diabetes: meta-analysis and systematic review. BMJ. 2012;344:e1454.

15. Suzuki N, Goto Y, Ota H, Kito K, Mano F, Joo E, Ikeda K, Inagaki N, Nakayama $\mathrm{T}$. Characteristics of the Japanese diet described in epidemiologic publications: a qualitative systematic review. J Nutr Sci Vitaminol (Tokyo). 2018;64:129-37.

16. Shimokata $\mathrm{H}$, Ando $\mathrm{F}$, Niino N. A new comprehensive study on aging--the National Institute for longevity sciences, longitudinal study of aging (NILSLSA). J Epidemiol. 2000;10:S1-9.

17. Imai T, Sakai S, Mori K, Ando F, Niino N, Shimokata H. Nutritional assessments of 3-day dietary records in National Institute for longevity sciences--longitudinal study of aging (NILS-LSA). J Epidemiol. 2000;10:S70-6.

18. Ministry of Health LaWJ: Japan National Health and Nutrition Survey 2011. In Japan National Health and Nutrition Survey Ministry of Health, Labour and Welfare (Japan) 2013.

19. Overview of Dietary Reference Intakes for Japanese (2015) [https://www mhlw.go.jp/file/06-Seisakujouhou-10900000-Kenkoukyoku/Overview.pdf].

20. Drewnowski A, Fulgoni $\vee$ 3rd. Nutrient profiling of foods: creating a nutrient-rich food index. Nutr Rev. 2008;66:23-39.

21. Drewnowski A, Fulgoni VL 3rd. Nutrient density: principles and evaluation tools. Am J Clin Nutr. 2014;99:1223S-8S.

22. Michels KB, Bingham SA, Luben R, Welch AA, Day NE. The effect of correlated measurement error in multivariate models of diet. Am J Epidemiol. 2004;160:59-67.

23. Singh P, Kumar R, Sabapathy SN, Bawa AS. Functional and edible uses of soy protein products. Compr Rev Food Sci Food Saf. 2008;7:14-28.

24. Di Noia J. Defining powerhouse fruits and vegetables: a nutrient density approach. Prev Chronic Dis. 2014;11:E95.

25. Valverde ME, Hernández-Pérez T, Paredes-López O. Edible mushrooms: improving human health and promoting quality life. Int J Microbiol. 2015; 2015:376387.

26. Asakura K, Uechi K, Masayasu S, Sasaki S. Sodium sources in the Japanese diet: difference between generations and sexes. Public Health Nutr. 2016;19: 2011-23.

27. Gabriel AS, Ninomiya K, Uneyama $\mathrm{H}$. The role of the Japanese traditional diet in healthy and sustainable dietary patterns around the world. Nutrients. 2018;10:173

28. McEvoy CT, Temple N, Woodside JV. Vegetarian diets, low-meat diets and health: a review. Public Health Nutr. 2012;15:2287-94.

29. Maria Luisa Poyatos G, Fernando P-R: Diet Quality Indices for Nutrition Assessment: Types and Applications. 2017

30. Zhang RH, Wang ZP, Fei Y, Zhou B, Zheng SS, Wang LJ, Huang LC, Jiang SY, Liu ZY, Jiang JX, Yu YX. The difference in nutrient intakes between Chinese and Mediterranean, Japanese and American diets. Nutrients. 2015;7:4661-88.

31. Hibbeln JR, Nieminen LR, Blasbalg TL, Riggs JA, Lands WE. Healthy intakes of n-3 and n-6 fatty acids: estimations considering worldwide diversity. Am J Clin Nutr. 2006:83:1483s-93s.

32. Bates B, Lennox A, Prentice A, Bates C, Swan G. National diet and nutrition survey. Headline results from years 1, 2 and 3 (combined) of the rolling Programme (2008/2009-2010/11). London: Department of Health; 2012.

33. The third Italian National Food Consumption Survey, INRAN-SCAI 2005-06 Part 1: Nutrient intakes in Italy. Nutrition, Metabolism and Cardiovascular Diseases 2011, 21:922-932.

34. Gil A, Martinez de Victoria E, Olza J. Indicators for the evaluation of diet quality. Nutr Hosp. 2015;31(Suppl 3):128-44.

35. Lichtman SW, Pisarska K, Berman ER, Pestone M, Dowling H, Offenbacher E, Weisel H, Heshka S, Matthews DE, Heymsfield SB. Discrepancy between selfreported and actual caloric intake and exercise in obese subjects. N Engl J Med. 1992;327:1893-8.
36. Ministry of Health LaWJ: Japan National Health and Nutrition Survey 2006. In Japan National Health and Nutrition Survey Ministry of Health, Labour and Welfare (Japan) 2009.

37. Ministry of Health LaWJ: Japan National Health and Nutrition Survey 2017. In Japan National Health and Nutrition Survey Ministry of Health, Labour and Welfare (Japan) 2018.

38. Murakami K, Livingstone MBE, Sasaki S. Thirteen-year trends in dietary patterns among Japanese adults in the National Health and nutrition survey 2003(-)2015: continuous westernization of the Japanese diet. Nutrients. $2018 ; 10$.

\section{Publisher's Note}

Springer Nature remains neutral with regard to jurisdictional claims in published maps and institutional affiliations.
Ready to submit your research? Choose BMC and benefit from:

- fast, convenient online submission

- thorough peer review by experienced researchers in your field

- rapid publication on acceptance

- support for research data, including large and complex data types

- gold Open Access which fosters wider collaboration and increased citations

- maximum visibility for your research: over $100 \mathrm{M}$ website views per year

At BMC, research is always in progress.

Learn more biomedcentral.com/submissions 